\title{
The impact of omega-3 polyunsaturated fatty acid supplementation on the incidence of cardiovascular events and complications in peripheral arterial disease: a systematic review and meta-analysis
}

Jennifer E Enns ${ }^{1,2}$, Azadeh Yeganeh ${ }^{1,2}$, Ryan Zarychanski, ${ }^{3,4}$, Ahmed M Abou-Setta ${ }^{4}$, Carol Friesen ${ }^{5}$, Peter Zahradka ${ }^{1,2,6}$ and Carla G Taylor ${ }^{1,2,6^{*}}$

\begin{abstract}
Background: Individuals with peripheral arterial disease are at higher risk for cardiovascular events than the general population. While supplementation with omega-3 polyunsaturated fatty acids (PUFA) has been shown to improve vascular function, it remains unclear if supplementation decreases serious clinical outcomes. We conducted a systematic review and meta-analysis to determine whether omega-3 PUFA supplementation reduces the incidence of cardiovascular events and complications in adults with peripheral arterial disease.

Methods: We searched five electronic databases (MEDLINE, EMBASE, CENTRAL, Scopus and the International Clinical Trials Registry Platform) from inception to 6 December 2013 to identify randomized trials of omega-3 PUFA supplementation (from fish or plant oils) that lasted $\geq 12$ weeks in adults with peripheral arterial disease. No language filters were applied. Data on trial design, population characteristics, and health outcomes were extracted. The primary outcome was major adverse cardiac events; secondary outcomes included myocardial infarction, cardiovascular death, stroke, angina, amputation, revascularization procedures, maximum and pain-free walking distance, adverse effects of the intervention, and quality of life. Trial quality was assessed using the Cochrane Risk of Bias tool.
\end{abstract}

Results: Of 741 citations reviewed, we included five trials enrolling 396 individuals. All included trials were of unclear or high risk of bias. There was no evidence of a protective association of omega-3 PUFA supplementation against major adverse cardiac events (pooled risk ratio $0.73,95 \% \mathrm{Cl} 0.22$ to $2.41, \rho^{2} 75 \%, 2$ trials, 288 individuals) or other serious clinical outcomes. Adverse events and compliance were poorly reported.

Conclusions: Our results showed that insufficient evidence exists to suggest a beneficial effect of omega-3 PUFA supplementation in adults with peripheral arterial disease with regard to cardiovascular events and other serious clinical outcomes.

Keywords: Omega-3 polyunsaturated fatty acid, Peripheral arterial disease, Intermittent claudication

\footnotetext{
* Correspondence: ctaylor@sbrc.ca

'Department of Physiology, University of Manitoba, Winnipeg, Canada

${ }^{2}$ Canadian Centre for Agri-Food Research in Health and Medicine, St.

Boniface Research Centre, R2019-351 Taché Ave, Winnipeg R2H 2A6, Canada

Full list of author information is available at the end of the article
} 


\section{Background}

Peripheral arterial disease is an atherosclerosis-induced blockage of non-coronary and non-cerebral arteries. Individuals diagnosed with peripheral arterial disease most often present with ischemic pain in the lower leg following exercise, and as the disease progresses, pain may also occur at rest [1]. The management of peripheral arterial disease includes therapies that reduce atherosclerotic disease progression and cardiovascular events, such as vasoactive drugs, statins, smoking cessation therapy, exercise, and in severe cases, angioplasty or bypass surgery [2]. Risk factor modification unfortunately has little effect on the primary symptom of peripheral arterial disease, intermittent claudication [2]. Peripheral arterial disease is estimated to occur in $5.9 \%$ of people older than 40 years, corresponding to 7.2 million affected individuals in the United States alone [3]. While nearly $60 \%$ of all individuals with peripheral arterial disease are asymptomatic [4], they are still at high risk for coronary heart disease due to the underlying presence of atherosclerosis. Cardiac events are the most common cause of death in persons with peripheral arterial disease [5].

Omega-3 polyunsaturated fatty acids (PUFA) are a group of dietary fats obtained from fish and plant oils that are reported to have a protective role in coronary heart disease and other cardiovascular complications [6]. Omega-3 PUFA may exert beneficial effects in cardiovascular disease by lowering hepatic triglyceride production and increasing clearance from the circulation [7], and by incorporating into phospholipids in cell membranes, thereby reducing the availability of substrates for the production of pro-inflammatory molecules [8]. Systematic reviews of omega-3 PUFA supplementation cohort studies and randomized controlled trials have focused primarily on the marine-sourced omega-3 PUFA eicosapentaenoic acid (EPA) and docosahexaenoic acid (DHA). Many of these reviews have demonstrated reductions in cardiovascular mortality in populations with and without established cardiovascular disease [6,9-14], while others have shown mixed results [15-18] or no benefits [19-21] following marine omega-3 PUFA supplementation. However, little is known about the role of the plant-based omega-3 PUFA alpha-linolenic acid (ALA) in cardiovascular disease, particularly in the high-risk population of individuals with peripheral arterial disease.

Given the high incidence of cardiovascular events in individuals with peripheral arterial disease [22] and the demonstrated benefits of omega-3 PUFA in individuals with cardiovascular disease [6], several clinical trials of omega-3 PUFA supplementation have been conducted in the peripheral arterial disease population. While some of these trials have shown improvements in vascular function [23-25] or inflammatory status [26], it is unclear if supplementation decreases the incidence of major adverse cardiovascular events and other relevant clinical outcomes. The objective of this systematic review was to determine whether dietary supplementation with fish and/or plantbased omega-3 PUFA reduces the incidence of cardiac events and complications in the high-risk population of peripheral arterial disease patients.

\section{Methods}

Using an a priori published protocol [27], we conducted a systematic review using methodological approaches outlined in the Cochrane Handbook for Systematic Reviewers [28] and reported according to the Preferred Reporting Items for Systematic Reviews and Meta-Analyses (PRISMA) criteria [29].

\section{Data sources and searches}

We searched the following bibliographic databases from inception to Dec 6, 2013: PubMed/MEDLINE (National Library of Science), EMBASE (Ovid), CENTRAL (Cochrane library - Wiley), followed by forward searching for key articles in Scopus. To identify ongoing and unpublished trials, we searched the World Health Organization's International Clinical Trials Registry Platform. We supplemented electronic searches by hand-searching the bibliographies of included trials, and relevant narrative and systematic reviews. Our search strategy used both controlled vocabulary and free text, and searches in MEDLINE and EMBASE were combined with a high-sensitivity filter for randomized controlled trials [28]. The detailed search strategy for MEDLINE is included in Table 1.

\section{Study selection}

To identify a population at high risk for cardiovascular events, we included only randomized trials of adults aged 40 years or older with established peripheral arterial disease, which was diagnosed by the presence of stable intermittent claudication and/or an ankle-brachial index $\leq 0.9$. The intervention period was required to be at least 12 weeks in duration to allow the intervention to impact cardiovascular function. The minimum intervention duration of 12 weeks was chosen based on studies of the appearance of dietary fatty acids in the plasma and blood cell plasma membranes (which are considered robust markers of omega-3 PUFA consumption), demonstrating that plasma membrane fatty acid composition changes are apparent within two weeks of a dietary fatty acid intervention [30]. Thus, it is feasible that downstream physiological effects of the diet could be demonstrated within 12 weeks. We included interventions with any omega-3 PUFA in diet or supplement form where the dose per day was reported and with appropriate comparators (i.e. placebo, omega-3 PUFA deficient diet or usual diet). We used a two-stage process for trial screening and selection employing standardized and piloted screening forms. 


\section{Table 1 Search strategy}

\begin{tabular}{|c|c|}
\hline 1. & (omega 3 fatty acid OR omega-3 fatty acid OR $n 3$ fatty acid OR n-3 fatty acid OR n-3 polyunsaturated fatty acid) \\
\hline 2. & (dietary supplement OR dietary supplementation OR dietary fat) \\
\hline 3. & (flax OR flaxseed OR flaxseed oil OR linseed oil) \\
\hline 4. & (fish OR fish oil OR fatty fish OR marine) \\
\hline 5. & (canola OR canola oil OR rapeseed oil) \\
\hline 6. & $\begin{array}{l}\text { (dietary supplements[MeSH Terms]) OR (dietary fats[MeSH Terms]) OR (flax[MeSH Terms]) OR (linseed oil[MeSH Terms]) OR } \\
\text { (fishes[MeSH Terms]) OR (fish oils[MeSH Terms]) }\end{array}$ \\
\hline 7. & (eicosapentaenoic acid OR EPA) \\
\hline 8. & (docosahexaenoic acids OR DHA) \\
\hline 9. & (alpha-linolenic acid OR ALA) \\
\hline 10. & $\begin{array}{l}\text { (fatty acids, omega-3[MeSH Terms]) OR (eicosapentaenoic acid[MeSH Terms]) OR (docosahexaenoic acids[MeSH Terms]) OR } \\
\text { (alpha-linolenic acid[MeSH Terms]) }\end{array}$ \\
\hline 11. & \#1 OR \#2 OR \#3 OR \#4 OR \#5 OR \#6 OR \#7 OR \#8 OR \#9 OR \#10 \\
\hline 12. & (peripheral arterial disease OR peripheral artery disease OR peripheral arterial diseases OR peripheral artery diseases) \\
\hline 13. & (peripheral vascular disease OR peripheral vascular diseases OR peripheral angiopathy OR peripheral angiopathies) \\
\hline 14. & (ankle brachial index OR ankle-brachial index OR ankle brachial indices OR ankle-brachial indices OR intermittent claudication) \\
\hline 15. & $\begin{array}{l}\text { (peripheral arterial disease[MeSH Terms]) OR (peripheral vascular diseases[MeSH Terms]) OR (ankle-brachial index[MeSH Terms]) } \\
\text { OR (intermittent claudication[MeSH Terms]) }\end{array}$ \\
\hline 16. & \#12 OR \#13 OR \#14 OR \#15 \\
\hline 17. & $\begin{array}{l}\text { (randomized controlled trial[pt] OR controlled clinical trial[pt] OR randomized[tiab] OR placebo[tiab] OR drug therapy[sh] OR } \\
\text { randomly[tiab] OR trial[tiab] OR groups[tiab]) NOT (animals[mh] NOT humans[mh]) }\end{array}$ \\
\hline 18. & \#11 AND \#16 AND \#17 \\
\hline
\end{tabular}

Two reviewers independently screened the titles and abstracts of the search results to determine whether each citation met the inclusion criteria. Trials published in languages other than English were translated, and the full text of citations classified as include or unclear were independently reviewed with reference to the predetermined inclusion and exclusion criteria. Discrepancies between reviewers were resolved through consensus or by discussion with a third reviewer, as required.

\section{Data extraction and quality assessment}

From each trial, two reviewers independently abstracted population characteristics (including age, body mass index, and diagnosis of peripheral arterial disease), number of participants, trial duration and follow-up, intervention design (including type and dose of omega-3 PUFA, comparators, and co-interventions), clinical health outcomes (incidence of major adverse cardiac events, myocardial infarction, cardiovascular death, angina, and stroke, amputation, symptom-driven revascularization procedures (e.g. bypass surgery), maximum and pain-free walking distance, and quality of life), and adverse effects. Any disagreements were resolved through consensus. Where data were incompletely or imprecisely reported, we contacted study authors for clarification. We assessed the internal validity of the included trials using the Cochrane Collaboration Risk of Bias Tool [31]. This tool consists of six domains, each of which is rated "low risk," "unclear risk," or "high risk." If one or more individual domains were assessed as having a high risk of bias, the overall rating was a high risk of bias. We considered the overall risk of bias low only if all components were rated as having a low risk of bias. We rated the risk of bias for all other trials as unclear. Information regarding methodological quality was used to guide subgroup analyses and to explore sources of heterogeneity.

\section{Data synthesis and analysis}

We conducted meta-analyses of the data from included trials using Review Manager (Version 5.2, The Cochrane Collaboration, Copenhagen, Denmark). Pooled binary data were weighted using the Mantel-Haenszel method, and presented as risk ratios (or Peto odds ratios for rare events) with 95\% confidence intervals (CI) [32]. Pooled continuous data were weighted by the inverse of variance and expressed as a weighted mean difference with 95\% CI. We explored and quantified statistical heterogeneity of the data using the I-squared test [33]. We assessed publication bias by viewing the overlap of confidence intervals and using funnel plot techniques. For the primary outcome of major adverse cardiac events, we performed the following a priori subgroup analyses: short versus extended duration of intervention, high versus low omega-3 PUFA dose (g/day), type of omega-3 PUFA (EPA, DHA, ALA, or a combination of these), supplements or capsules vs. dietary sources of omega-3 PUFA, and the duration of follow-up. 
Final subgroup analyses were limited by the number of trials included and the availability of reported outcomes and covariates.

\section{Results}

Characteristics of trial populations and interventions

Of 741 citations identified from electronic and handsearches, we included 5 unique trials enrolling a total of 396 individuals (Figure 1; Table 2). All were single-centre trials published between 1990 and 2010. All trials were adjudicated to be of high (3/5) [34-36] or unclear (2/5) $[37,38]$ risk of bias (Table 3). Due to the small number of trials included, formal assessment of reporting bias (e.g., by using a funnel plot) was not possible.

Four trials were conducted in Europe [34-37] and one in Japan [38]. One trial recruited individuals who were diagnosed with peripheral arterial disease and were also hypercholesterolemic and on statin therapy [38]. One trial included individuals who previously had angina or a myocardial infarction [34], while the rest excluded individuals with a recent history of cardiovascular/cerebrovascular events or revascularization surgery. Three trials $[34,37,38]$ studied capsules containing varying doses of EPA alone or EPA and DHA combined, compared to capsules of sunflower oil [34] or corn oil [37], or no treatment [38]. The intervention in the remaining two trials $[35,36]$ studied a specially developed dairy product enriched with EPA, DHA and ALA, as well as vitamins $\mathrm{A}, \mathrm{B}_{6}, \mathrm{D}$ and $\mathrm{E}$, folate and oleic acid, compared to a control group who received a product identical in appearance enriched only with vitamins A and D. None of the trials had follow-up periods beyond the duration of the intervention.

\section{Risk of bias in included trials}

While all trials had random sequence generation (5/5), fewer reported adequate allocation concealment $(2 / 5)$ [34,37] and blinding of outcome assessment (3/5) [34-36], and all trials were subject to unclear or high risk of attrition bias due to incomplete outcome data following substantial loss to follow-up or poor reporting of outcomes (5/5) (Table 3). The presence of co-intervention nutrients in 3/5 trials [34-36] did not allow proper controlling for omega-3 PUFA effect.

\section{Major adverse cardiac events}

Two trials reported the incidence of major adverse cardiac events following an intervention with EPA only $[34,38]$. The risk ratio for major adverse cardiac events was not significantly decreased with supplementation

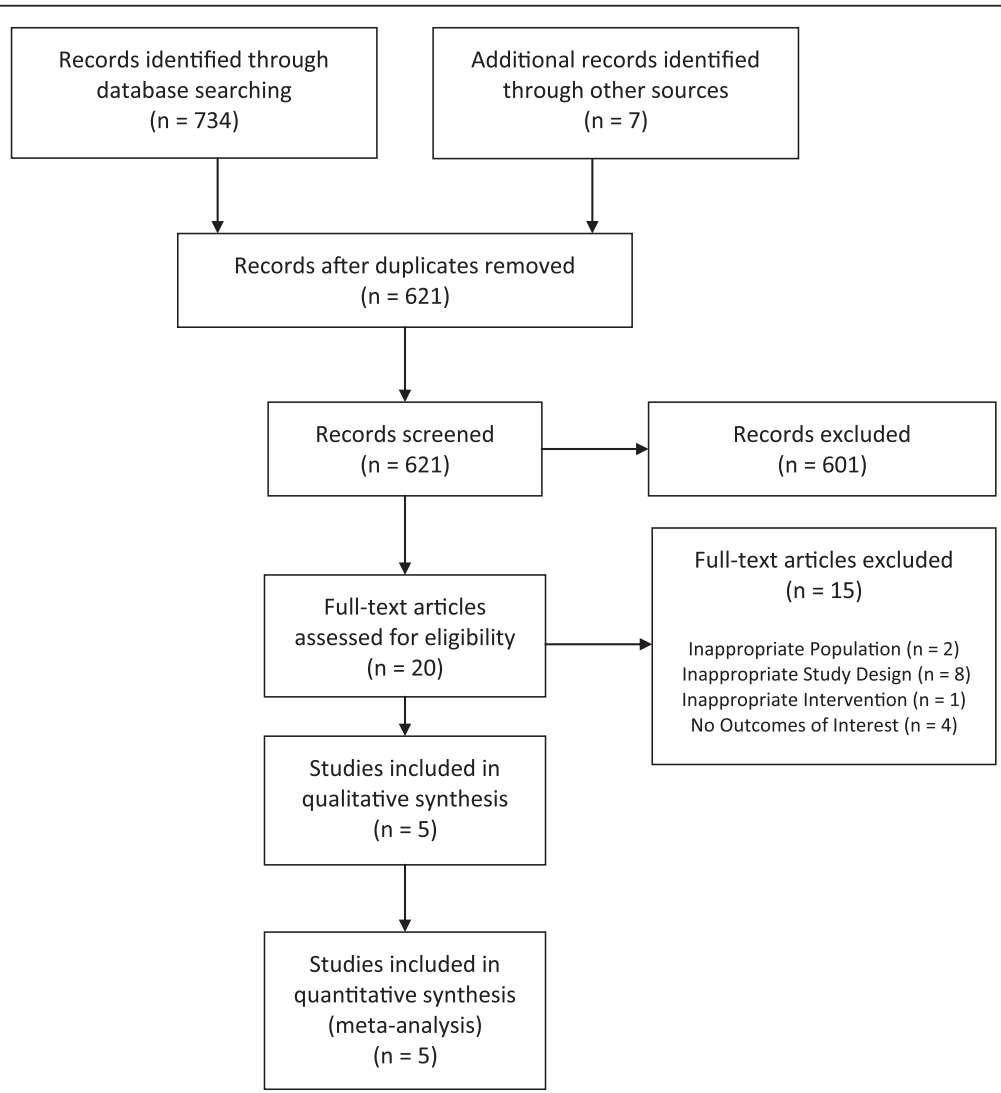

Figure 1 PRISMA flow diagram. Summary of the evidence search and selection. 


\section{Table 2 Patient populations and study characteristics}

\begin{tabular}{|c|c|c|c|c|c|c|c|c|c|}
\hline \multirow[t]{2}{*}{ Study } & \multicolumn{5}{|c|}{ Population } & \multicolumn{4}{|c|}{ Intervention } \\
\hline & $\begin{array}{c}\text { Age } \\
\text { (years) }\end{array}$ & $\begin{array}{c}\mathrm{BMI} \\
\left(\mathrm{kg} / \mathrm{m}^{2}\right)\end{array}$ & Diagnosis of PAD & Medication/therapy & Co-morbidities & $\begin{array}{c}\text { Omega-3 } \\
\text { PUFA (g/day) }\end{array}$ & $\begin{array}{c}\text { Comparator } \\
\text { (g/day) }\end{array}$ & Co-intervention & Duration \\
\hline $\begin{array}{l}\text { Gans } \\
1990[37]\end{array}$ & $66.1 \pm 8.2$ & NR & $\begin{array}{l}\text { Treadmill testing for IC } \\
\text { classification; IC stable } \\
\text { for } \geq 1 \mathrm{yr}\end{array}$ & $\begin{array}{l}\text { Excluded patients on } \\
\text { lipid-lowering or } \\
\text { platelet-active drugs }\end{array}$ & None reported & $\begin{array}{c}\mathrm{EPA}(1.8)+\mathrm{DHA} \\
(1.2)\end{array}$ & Corn oil (3.0) & None & $16 w k$ \\
\hline $\begin{array}{l}\text { Leng } \\
1998 \text { [34] }\end{array}$ & $65.7 \pm 7.1$ & $26.7 \pm 4.2$ & $\begin{array}{l}\text { Edinburgh Claudication } \\
\text { Questionnaire; IC stable } \\
\text { for } \geq 6 \text { mth; ABI < } 0.9\end{array}$ & $\begin{array}{l}\text { Included patients } \\
\text { taking aspirin }\end{array}$ & $\begin{array}{l}\text { Excluded patients with critical } \\
\text { ischemia, previous or impending } \\
\text { surgery, unstable angina or } \mathrm{Ml}_{\text {, }} \\
\text { or severe concurrent illnesses }\end{array}$ & EPA $(0.18-0.27)$ & $\begin{array}{l}\text { Sunflower oil } \\
(2.0-3.0)\end{array}$ & $\begin{array}{l}\text { Gamma-linolenic } \\
\text { acid }\end{array}$ & $2 \mathrm{yr}$ \\
\hline $\begin{array}{l}\text { Carrero } \\
2005[35]\end{array}$ & $64.0 \pm 9.0$ & $27.9 \pm 3.9$ & Presence of $|C ; A B|<0.7$ & $\begin{array}{l}\text { Excluded patients eligible } \\
\text { for vascular surgery; excluded } \\
\text { patients taking statins }\end{array}$ & $\begin{array}{l}\text { Excluded patients with history of } \\
\text { cardiac events or with endocrine } \\
\text { or metabolic disturbances. Included } \\
\text { patients who were smokers, had } \\
\text { T2D or hypertension }\end{array}$ & $\begin{array}{c}E P A(0.2)+D H A \\
(0.13)+A L A(0.06)\end{array}$ & $\begin{array}{l}\text { Placebo (dairy } \\
\text { product) }\end{array}$ & $\begin{array}{l}\text { Vitamins } B_{6} \text { and } E_{1} \\
\text { folate, oleic acid }\end{array}$ & $1 \mathrm{yr}$ \\
\hline $\begin{array}{l}\text { Carrero } \\
2006[36]\end{array}$ & $65.5 \pm 9.5$ & $27.7 \pm 3.4$ & Presence of $|C ; A B|<0.7$ & $\begin{array}{l}\text { Excluded patients eligible } \\
\text { for vascular surgery; excluded } \\
\text { patients taking statins }\end{array}$ & $\begin{array}{l}\text { Excluded patients with history of } \\
\text { cardiac events or with endocrine or } \\
\text { metabolic disturbances. Included } \\
\text { patients who were smokers, } \\
\text { had T2D or hypertension }\end{array}$ & $\begin{array}{c}E P A(0.2)+D H A \\
(0.13)+A L A(0.06)\end{array}$ & $\begin{array}{l}\text { Placebo (dairy } \\
\text { product) }\end{array}$ & $\begin{array}{l}\text { Vitamins } B_{6} \text { and } E_{1} \\
\text { folate, oleic acid }\end{array}$ & $1 \mathrm{yr}$ \\
\hline $\begin{array}{l}\text { Ishikawa } \\
2010[38]\end{array}$ & $65.2 \pm 7.4$ & $23.3 \pm 2.8$ & $\begin{array}{l}\text { Presence of IC; physical } \\
\text { findings (e.g. ulcer) } \\
\text { and } A B \mid\end{array}$ & $\begin{array}{l}\text { All patients included were } \\
\text { taking statins }\end{array}$ & $\begin{array}{l}\text { Hyperlipidemia (total } \\
\text { serum cholesterol) }\end{array}$ & EPA (1.8) & No treatment & Simvastatin or Pravastatin & up to $5 \mathrm{yr}$ \\
\hline
\end{tabular}

Data are presented as mean \pm SD. ABI: ankle-brachial index; ALA: alpha-linolenic acid; BMI: body mass index; DHA: docosahexaenoic acid; EPA: eicosapentaenoic acid; IC: intermittent claudication; MI: myocardial infarction; T2D: type 2 diabetes. 
Table 3 Risk of bias assessment

\begin{tabular}{|c|c|c|c|c|c|c|c|}
\hline \multirow[t]{2}{*}{ Study } & \multicolumn{2}{|c|}{ Selection bias } & \multirow{2}{*}{$\begin{array}{c}\text { Performance bias } \\
\text { Blinding of participants } \\
\text { and personnel }\end{array}$} & \multirow{2}{*}{$\begin{array}{l}\text { Attrition bias } \\
\text { Incomplete } \\
\text { outcome data }\end{array}$} & \multirow{2}{*}{$\begin{array}{l}\text { Reporting bias } \\
\text { Selective } \\
\text { reporting } \\
\end{array}$} & \multirow{2}{*}{$\begin{array}{l}\text { Other sources } \\
\text { of bias }\end{array}$} & \multirow{2}{*}{$\begin{array}{c}\text { Overall risk } \\
\text { of bias }\end{array}$} \\
\hline & $\begin{array}{c}\text { Random sequence } \\
\text { generation }\end{array}$ & $\begin{array}{c}\text { Allocation } \\
\text { concealment }\end{array}$ & & & & & \\
\hline Gans 1990 [37] & Low risk & Low risk & Unclear risk & Unclear risk & Unclear risk & Low risk & Unclear risk \\
\hline Leng 1998 [34] & Low risk & Low risk & Low risk & High risk" & Unclear risk & Unclear risk* & High risk \\
\hline Carrero 2005 [35] & Low risk & Unclear risk & Low risk & Unclear risk & Unclear risk & High risk ${ }^{\S}$ & High risk \\
\hline Carrero 2006 [36] & Low risk & Unclear risk & Low risk & Unclear risk & Unclear risk & High risk ${ }^{\S}$ & High risk \\
\hline Ishikawa 2010 [38] & Low risk & Unclear risk & Unclear risk & Unclear risk & Unclear risk & Low risk & Unclear risk \\
\hline
\end{tabular}

*Intervention group received gamma-linolenic acid, which was not supplied in control.

sIntervention group received vitamins $\mathrm{B}_{6}$ and $\mathrm{E}$, folate and oleic acid, which were not supplied in control.

"Drop-out rate was $>30 \%$.

of EPA (risk ratio 0.73 ; $95 \%$ CI 0.22 to $2.41 ; I^{2} 75 \% ; 2$ trials [34,38]; 288 individuals; Figure 2). High statistical heterogeneity observed may relate to differences in the trial populations (Japanese vs. British, hyper- vs. normocholesterolemic), the ten-fold difference in daily dose of EPA ( $1.8 \mathrm{~g}$ vs. $0.18 \mathrm{~g}$ ), the comparator in the control group (no treatment vs. sunflower oil), the co-intervention (statins vs. gamma-linolenic acid), or the length of the intervention (five vs. two years). In one of the trials (213 individuals), the risk ratio for major adverse cardiac events associated with $1.8 \mathrm{~g} /$ day EPA compared to no treatment for 5 years was $0.41 ; 95 \%$ CI 0.19 to 0.87 [38]. In the second trial (75 individuals) comparing $0.18 \mathrm{~g} /$ day EPA to sunflower oil for 2 years, the risk ratio for major adverse cardiac events was 1.38; 95\% CI 0.55 to 3.50 [34].

\section{Secondary clinical outcomes}

Two trials with a total of 288 individuals reported the incidence of myocardial infarction, cardiovascular death and revascularization procedures (Table 4) [34,38]. The pooled Peto odds ratios for myocardial infarction (Peto odds ratio $0.64 ; 95 \%$ CI 0.22 to 1.88 ), cardiovascular death (Peto odds ratio $0.60,95 \%$ CI 0.19 to 1.90 ) and the pooled risk ratio for revascularization surgery (risk ratio
0.81, 95\% CI, 0.13 to 4.91 ) demonstrated no significant difference between the EPA intervention group and control (no treatment or sunflower oil).

Four trials [34-37] with a total of 187 individuals reported pain-free walking distance (metres), an indicator of intermittent claudication (Figure 3). We observed considerable heterogeneity and no statistically significant differences in pain-free walking distance associated with omega-3 PUFA supplementation (mean difference 115.40 metres; $95 \%$ CI -42.24 to $273.05 ; I^{2} 89 \%$ ). None of the trials reported on quality of life. The remaining secondary outcomes (stroke, angina, amputation and maximum walking distance) were each reported by only one trial and were not found to be statistically different with omega-3 PUFA intervention (Table 4). Gastrointestinal upset, reported in a single trial [34], was more frequent with EPA treatment (risk ratio 1.58; $95 \%$ CI 1.01 to 2.48 ; 60 individuals).

\section{Subgroup analyses}

Limitations of the data (i.e. the number of trials included, and the availability of appropriate outcome data and covariates reported) precluded most subgroup analyses. Comparisons of the effects of omega-3 PUFA intervention length, dose and type of omega-3 PUFA on pain-free

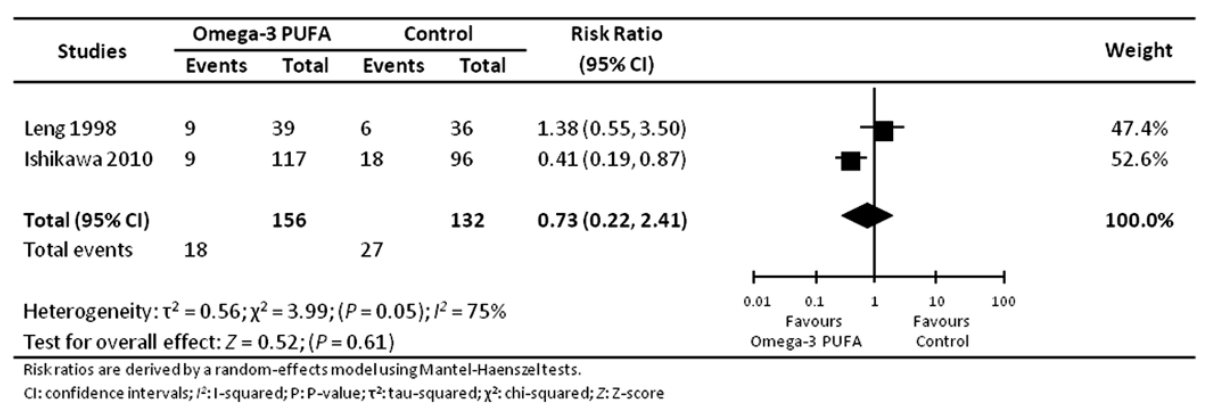

Figure 2 Effect of omega-3 PUFA supplementation on major adverse cardiac events in individuals with peripheral arterial disease. 
Table 4 Secondary outcome measures

\begin{tabular}{|c|c|c|c|c|c|}
\hline \multirow[t]{2}{*}{ Outcome } & \multirow[t]{2}{*}{$\begin{array}{l}\text { No. of } \\
\text { trials }\end{array}$} & \multicolumn{2}{|c|}{$\begin{array}{l}\text { No. of events/total } \\
\text { patients in cohort }\end{array}$} & \multirow[t]{2}{*}{$\begin{array}{l}\text { Effect estimate } \\
\quad(95 \% \mathrm{Cl})\end{array}$} & \multirow[t]{2}{*}{$r^{2}$} \\
\hline & & Omega-3 PUFA & Control & & \\
\hline Myocardial Infarction (Leng 1998 [34], Ishikawa 2010 [38]) & 2 & $6 / 156$ & $8 / 132$ & Peto OR, $0.64(0.22,1.88)$ & $0 \%$ \\
\hline Cardiovascular Death (Leng 1998 [34], Ishikawa 2010 [38]) & 2 & $5 / 156$ & $7 / 132$ & Peto OR, $0.60(0.19,1.90)$ & $0 \%$ \\
\hline Stroke (Leng 1998 [34]) & 1 & $3 / 60$ & $1 / 60$ & Peto OR, $2.79(0.38,20.31)$ & NE \\
\hline Angina (Ishikawa 2010 [38]) & 1 & $5 / 117$ & $8 / 106$ & $R R, 0.57(0.19,1.68)$ & NE \\
\hline \multicolumn{6}{|l|}{ Adverse Effects } \\
\hline All Adverse Events (Gans 1990 [37], Leng 1998 [34]) & 2 & $17 / 76$ & $21 / 76$ & RR $0.81(0.48,1.38)$ & NE \\
\hline Gastrointestinal Upset (Leng 1998 [34]) & 1 & $30 / 60$ & $19 / 60$ & RR $1.58(1.01,2.48)$ & NE \\
\hline Revascularization Surgery (Leng 1998 [34], Ishikawa 2010 [38]) & 2 & $9 / 156$ & $13 / 132$ & $\mathrm{RR}, 0.81(0.13,4.91)$ & $59 \%$ \\
\hline Amputation (Leng 1998 [34]) & 1 & $0 / 60$ & $1 / 60$ & Peto OR, $0.14(0.00,6.82)$ & NE \\
\hline $\begin{array}{l}\text { Pain-Free Walking Distance (Gans } 1990 \text { [37], Leng } 1998 \text { [34], } \\
\text { Carrero } 2005 \text { [35], Carrero } 2006 \text { [36]) }\end{array}$ & 4 & 95 & 88 & MD, $115.40(-42.24,273.05)$ & $89 \%$ \\
\hline Maximum Walking Distance (Gans 1990 [37]) & 1 & 16 & 16 & MD, -26.00 (-71.92, 19.92) & $\mathrm{NE}$ \\
\hline
\end{tabular}

Walking distances (mean differences) are expressed in metres.

$\mathrm{Cl}$ : confidence interval; MD: mean difference; NE: not estimable; OR: odds ratio; RR: risk ratio; $I^{2}$ : I-squared.

walking distance did not reach significance, and statistical heterogeneity remained high (Table 5).

\section{Discussion}

In this systematic review and meta-analysis of omega-3 PUFA in adults with peripheral arterial disease, we found no evidence to suggest a protective association between omega-3 PUFA supplementation and clinical cardiovascular outcomes, including myocardial infarction, cardiovascular death, angina, stroke, amputation, revascularization, pain-free walking distance or quality of life. One trial indicated that omega-3 PUFA intake may be associated with increased gastrointestinal side effects.

The effect of omega-3 PUFA supplementation in cardiovascular disease is controversial. Some reviews and metaanalyses have demonstrated reductions in adverse events with both plant-based ALA and marine-sourced EPA and DHA supplementation in cardiovascular $[9-14,39]$ and cerebrovascular disease [40], and marine omega-3
PUFA may be effective in preventing atrial fibrillation after cardiac surgery [41,42], although this finding remains controversial [43]. Other reviews have demonstrated mixed [6,15-18] or no benefits [19-21] following marine and/or plant-based omega-3 PUFA supplementation. In peripheral arterial disease populations, supplementation with EPA and DHA has been shown to significantly reduce measures of arterial stiffness in several cohorts, including healthy and overweight individuals, and individuals with cardiovascular risk factors, type 2 diabetes, or hypertension [23-25,44]. Even so, adequate long-term data on serious adverse events in peripheral arterial disease populations is lacking.

In this review, the small number of trials available and the lack of uniformity in population and design of the included trials contributed to the relatively high statistical heterogeneity for some outcomes, and thus caution must be exercised in interpreting these results. Some of the key differences among the included trials included

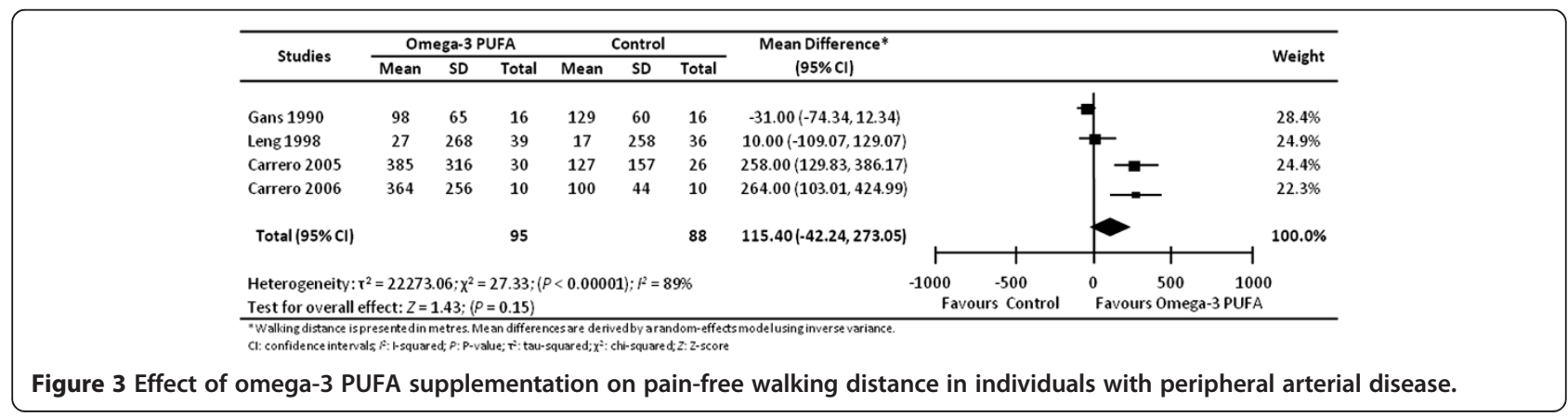


Table 5 Subgroup analysis: omega-3 PUFA and pain-free walking distance

\begin{tabular}{|c|c|c|c|c|c|}
\hline \multirow[t]{2}{*}{ Subgroup } & \multirow[t]{2}{*}{$\begin{array}{l}\text { No. of } \\
\text { trials }\end{array}$} & \multicolumn{2}{|c|}{$\begin{array}{l}\text { Total patients } \\
\text { in cohort }\end{array}$} & \multirow[t]{2}{*}{ Effect estimate $(95 \% \mathrm{Cl})$} & \multirow[t]{2}{*}{$r^{2}$} \\
\hline & & Omega-3 PUFA & Control & & \\
\hline \multicolumn{6}{|l|}{ Effect of Intervention Duration on PFWD } \\
\hline Less than 6 months (Gans 1990 [37]) & 1 & 16 & 16 & $M D,-31.00(-74.34,12.34)$ & NE \\
\hline $\begin{array}{l}6 \text { months or longer (Leng } 1998 \text { [34], } \\
\text { Carrero } 2005 \text { [35], Carrero } 2006 \text { [36]) }\end{array}$ & 3 & 79 & 72 & MD, $172.98(-0.82,346.77)$ & $80 \%$ \\
\hline \multicolumn{6}{|l|}{ Effect of Omega-3 PUFA Dose on PFWD } \\
\hline More than $0.3 \mathrm{~g} /$ day (Gans 1990 [37]) & 1 & 16 & 16 & $M D,-31.00(-74.34,12.34)$ & $\mathrm{NE}$ \\
\hline $\begin{array}{l}\text { Less than or equal to } 0.3 \mathrm{~g} / \text { day (Leng } 1998 \text { [34], } \\
\text { Carrero } 2005 \text { [36], Carrero } 2006 \text { [37]) }\end{array}$ & 3 & 79 & 72 & MD, $172.98(-0.82,346.77)$ & $80 \%$ \\
\hline \multicolumn{6}{|l|}{ Effect of Omega-3 PUFA Type on PFWD } \\
\hline $\begin{array}{l}\text { EPA + DHA + ALA (Carrero } 2005 \text { [35], } \\
\text { Carrero } 2006 \text { [36]) }\end{array}$ & 2 & 40 & 36 & MD, $260.33(160.05,360.60)$ & $0 \%$ \\
\hline EPA + DHA (Gans $1990[37])$ & 1 & 16 & 16 & $M D,-31.00(-74.34,12.34)$ & NE \\
\hline EPA (Leng 1998 [34]) & 1 & 39 & 36 & MD, $10.00(-109.07,129.07)$ & NE \\
\hline
\end{tabular}

ALA, alpha-linolenic acid; Cl, confidence intervals; DHA, docosahexaenoic acid; EPA, eicosapentaenoic acid; MD, mean difference; PFWD, pain-free walking distance; $I^{2}$, I-squared.

geographic differences (e.g., the Japanese population's omega-3 PUFA consumption is up to 15 times greater than in Western countries $[45,46])$, variable intervention durations (from 16 weeks up to several years), differences in doses of omega-3 PUFA (doses of $0.13 \mathrm{~g} /$ day DHA and $0.2 \mathrm{~g} /$ day EPA are probably too low to have an effect), and concomitant statin and vitamin therapy in some trials (which may have provided beneficial effects on cardiovascular function [47]). Finally, the potential influence of the trial sponsor should also not go unnoticed as trials conducted by Carrero et al. $[35,36]$ were sponsored by the manufacturers of omega-3 PUFA.

Only two of the included trials $[37,38]$ supplied therapeutic omega-3 PUFA doses of $>1 \mathrm{~g} /$ day, according to the recommendations from the American Heart Association and the World Health Organization [48,49]. Subgroup analyses suggest that a longer period of treatment (6 months or longer) even at a low omega-3 PUFA dose may improve walking distance. This exploratory finding must be confirmed in future studies. It should also be noted that only two trials $[34,37]$ reported on adverse side effects: while the trial by Gans et al. [37] reported no significant adverse effects, half of the individuals in the omega-3 PUFA group in the trial conducted by Leng et al. [34] experienced gastrointestinal upset. Growing recognition for nutritional components and supplements as therapeutic agents highlights the need for thorough safety testing during clinical trials.

The internal validity of the trials was often unclear due to underreporting of methods, which potentially could have biased the results. All of the trials rated poorly in the risk of bias assessment, mostly due to a lack of detailed reporting and uncertainty around the true effect of omega-3 PUFA alone (Table 3). If meaningful and reliable results are to be obtained from future randomized controlled trials, substantial improvements in trial design must be made to reduce the risk of bias, ensure sufficient statistical power, and test for the effect of omega-3 PUFA without confounding factors.

Strengths of this review include the broad bibliographic screening of multiple citation databases and trial registries, and rigorous testing for bias. We focused on patientcentred outcomes and evaluated efficacy in the context of relevant side effects. We used an a priori published protocol and followed established methodological guidelines in the conduct and reporting of this review. It should be noted that the results of the recent update to the Cochrane review on omega-3 PUFA supplementation in individuals with intermittent claudication [50] are in agreement with our findings, with very little indication for recommending omega-3 PUFA as a therapeutic approach in individuals with peripheral arterial disease. However, the focus of the Cochrane review was primarily on marine omega-3 PUFA, and the presence of ALA in some of the interventions was not acknowledged.

Limitations of this review include the restricted amount of clinical outcome data available for pooling among trials, which may have affected the overall findings. We chose to pool data from trials that were variable in intervention design and population.

\section{Conclusions}

In individuals with peripheral arterial disease, insufficient evidence exists to suggest a beneficial effect of omega-3 PUFA supplementation with regard to major adverse cardiac events, need for revascularization or amputation, pain-free walking disease, or quality of life. Rigorously 
designed randomized trials powered to detect these clinically relevant outcomes are needed to establish the efficacy and safety of omega-3 PUFA in individuals with peripheral arterial disease.

\section{Abbreviations}

ABI: Ankle-brachial index; ALA: Alpha-linolenic acid; BMl: Body mass index; Cl: Confidence interval; DHA: Docosahexaenoic acid; EPA: Eicosapentaenoic acid; I': I-squared; IC: Intermittent claudication; MD: Mean difference; MI: Myocardial infarction; NE: Not estimable; OR: Odds ratio; PFWD: Pain-free walking distance; PUFA: Polyunsaturated fatty acid; T2D: Type 2 diabetes.

\section{Competing interests}

No funding was obtained specifically for this systematic review. JE is supported by a Food Advancement through Science and Training (FAST) scholarship through the National Sciences and Engineering Research Council's Collaborative Research and Training Experience (CREATE) program. The authors declare no conflicts of interest.

\section{Authors' contributions}

An expert in vascular and metabolic disease (JE) led the review team, which included a panel of content experts from multiple fields: vascular physiology (PZ), lipid nutrition (CGT), and research methodology (RZ, AMAS). All authors assisted in formulating the review question, CF assisted with developing the search strategies, RZ and AMAS guided the review methods, and AY assisted with screening and data extraction throughout the review process. JE drafted the manuscript with input from all other authors. All authors read and approved the final manuscript.

\section{Acknowledgements}

We acknowledge the University of Manitoba Libraries Open Access Author's Fund for covering the article processing fees.

\section{Author details}

'Department of Physiology, University of Manitoba, Winnipeg, Canada. ${ }^{2}$ Canadian Centre for Agri-Food Research in Health and Medicine, St. Boniface Research Centre, R2019-351 Taché Ave, Winnipeg R2H 2A6, Canada. ${ }^{3}$ Department of Internal Medicine, University of Manitoba, Health Sciences Centre, 820 Sherbrook St, Winnipeg R3T 2N2, Canada. ${ }^{4}$ George \& Fay Yee Centre for Healthcare Innovation/Winnipeg Regional Health Authority, Health Sciences Centre, University of Manitoba, 820 Sherbrook St, Winnipeg R3T 2N2, Canada. ${ }^{5}$ Neil John Maclean Health Sciences Library, University of Manitoba Libraries, 770 Bannatyne Ave, Winnipeg R3E OW3, Canada. ${ }^{6}$ Department of Human Nutritional Sciences, University of Manitoba, Winnipeg, Canada.

Received: 17 March 2014 Accepted: 28 May 2014

Published: 31 May 2014

\section{References}

1. What is peripheral arterial disease? http://www.nhlbi.nih.gov/health/ health-topics/topics/pad/.

2. Dobesh PP, Stacy ZA, Persson EL: Pharmacologic therapy for intermittent claudication. Pharmacotherapy 2009, 29(5):526-553.

3. Pande RL, Perlstein TS, Beckman JA, Creager MA: Secondary prevention and mortality in peripheral artery disease: National Health and Nutrition Examination Study, 1999 to 2004. Circulation 2011, 124(1):17-23.

4. Leng GC, Papacosta O, Whincup P, Wannamethee G, Walker M, Ebrahim S, Nicolaides AN, Dhanjil S, Griffin M, Belcaro G, Rumley A, Lowe GD: Femoral atherosclerosis in an older British population: prevalence and risk factors. Atherosclerosis 2000, 152(1):167-174.

5. Norgren L, Hiatt WR, Dormandy JA, Nehler MR, Harris KA, Fowkes FG, TASC II Working Group: Inter-society consensus for the management of peripheral arterial disease (TASC II). J Vasc Surg 2007, 45(Suppl S):S5-S67.

6. Mozaffarian D, Wu JH: Omega-3 fatty acids and cardiovascular disease: effects on risk factors, molecular pathways, and clinical events. J Am Coll Cardiol 2011, 58(20):2047-2067.

7. Harris WS, Miller M, Tighe AP, Davidson MH, Schaefer EJ: Omega-3 fatty acids and coronary heart disease risk: clinical and mechanistic perspectives. Atherosclerosis 2008, 197(1):12-24.
8. Calder PC: Polyunsaturated fatty acids and inflammatory processes: new twists in an old tale. Biochimie 2009, 91(6):791-795.

9. Bucher $\mathrm{HC}$, Hengstler $\mathrm{P}$, Schindler $\mathrm{C}$, Meier $\mathrm{G}$ : $\mathrm{N}-3$ polyunsaturated fatty acids in coronary heart disease: a meta-analysis of randomized controlled trials. Am J Med 2002, 112(4):298-304.

10. Mozaffarian D, Rimm EB: Fish intake, contaminants, and human health evaluating the risks and the benefits. JAMA 2006, 296(15):1885-1899.

11. Marik PE, Varon J: Omega-3 dietary supplements and the risk of cardiovascular events: a systematic review. Clin Cardiol 2009, 32(7):365-372.

12. Leon H, Shibata MC, Sivakumaran S, Dorgan M, Chatterley T, Tsuyuki RT: Effect of fish oil on arrhythmias and mortality: systematic review. BMJ 2008, 337:a2931.

13. Mente A, de Koning L, Shannon HS, Anand SS: A systematic review of the evidence supporting a causal link between dietary factors and coronary heart disease. Arch Intern Med 2009, 169(7):659-669.

14. Delgado-Lista J, Perez-Martinez P, Lopez-Miranda J, Perez-Jimenez F: Long chain omega-3 fatty acids and cardiovascular disease: a systematic review. Br J Nutr 2012, 107(Suppl 2):S201-S213.

15. Zhao YT, Chen Q, Sun YX, Li XB, Zhang P, Xu Y, Guo JH: Prevention of sudden cardiac death with omega- 3 fatty acids in patients with coronary heart disease: a meta-analysis of randomized controlled trials. Ann Med 2009, 41(4):301-310.

16. Filion KB, El Khoury F, Bielinski M, Schiller I, Dendukuri N, Brophy JM: Omega-3 fatty acids in high-risk cardiovascular patients: a meta-analysis of randomized controlled trials. BMC Cardiovasc Disord 2010, 10:24-2261-10-24.

17. Chen $Q$, Cheng LQ, Xiao TH, Zhang YX, Zhu M, Zhang R, Li K, Wang Y, Li Y: Effects of omega-3 fatty acid for sudden cardiac death prevention in patients with cardiovascular disease: a contemporary meta-analysis of randomized, controlled trials. Cardiovasc Drugs Ther 2011, 25(3):259-265.

18. Effects of eicosapentaenoic acid and docosahexaenoic acid on mortalty across diverse settings: systematic review and meta-analysis of randomized trials and prospective cohorts. 2012, http://www.ncbi.nlm.nih.gov/pubmed health/PMH0041092/.

19. Hooper L, Thompson RL, Harrison RA, Summerbell CD, Ness AR, Moore HJ, Worthington HV, Durrington PN, Higgins JP, Capps NE, Riemersma RA, Ebrahim SB, Davey Smith G: Risks and benefits of omega 3 fats for mortality, cardiovascular disease, and cancer: systematic review. BMJ 2006, 332(7544):752-760

20. Kwak SM, Myung SK, Lee YJ, Seo HG, Korean Meta-analysis Study Group: Efficacy of omega-3 fatty acid supplements (eicosapentaenoic acid and docosahexaenoic acid) in the secondary prevention of cardiovascular disease: a meta-analysis of randomized, double-blind, placebo-controlled trials. Arch Intern Med 2012, 172(9):686-694.

21. Rizos EC, Ntzani EE, Bika E, Kostapanos MS, Elisaf MS: Association between omega-3 fatty acid supplementation and risk of major cardiovascular disease events: a systematic review and meta-analysis. JAMA 2012, 308(10):1024-1033.

22. Sprengers RW, Janssen K, Moll FL, Verhaar MC, van der Graaf Y, SMART Study Group: Prediction rule for cardiovascular events and mortality in peripheral arterial disease patients: data from the prospective Second Manifestations of ARTerial disease (SMART) cohort study. J Vasc Surg 2009, 50(6):1369-1376.

23. West SG, Krick AL, Klein LC, Zhao G, Wojtowicz TF, McGuiness M, Bagshaw DM, Wagner P, Ceballos RM, Holub BJ, Kris-Etherton PM: Effects of diets high in walnuts and flax oil on hemodynamic responses to stress and vascular endothelial function. J Am Coll Nutr 2010, 29(6):595-603.

24. Schiano V, Laurenzano E, Brevetti G, De Maio Jl, Lanero S, Scopacasa F, Chiariello M: Omega-3 polyunsaturated fatty acid in peripheral arterial disease: effect on lipid pattern, disease severity, inflammation profile, and endothelial function. Clin Nutr 2008, 27(2):241-247.

25. Woodcock BE, Smith E, Lambert WH, Jones WM, Galloway JH, Greaves M, Preston FE: Beneficial effect of fish oil on blood viscosity in peripheral vascular disease. Br Med J (Clin Res Ed) 1984, 288(6417):592-594.

26. Madden J, Shearman CP, Dunn RL, Dastur ND, Tan RM, Nash GB, Rainger GE, Brunner A, Calder PC, Grimble RF: Altered monocyte CD44 expression in peripheral arterial disease is corrected by fish oil supplementation. Nutr Metab Cardiovasc Dis 2009, 19(4):247-252.

27. PROSPERO International prospective register of systematic reviews. http:// www.crd.york.ac.uk/PROSPERO/display_record.asp?ID=CRD42013005488\#. U5dUD_IdVOI. 
28. Cochrane handbook for systematic reviews of interventions. www. cochrane-handbook.org.

29. Liberati A, Altman DG, Tetzlaff J, Mulrow C, Gotzsche PC, loannidis JP, Clarke M, Devereaux PJ, Kleijnen J, Moher D: The PRISMA statement for reporting systematic reviews and meta-analyses of studies that evaluate health care interventions: explanation and elaboration. J Clin Epidemio/ 2009, 62(10):e1-e34.

30. Hodson L, Eyles HC, McLachlan KJ, Bell ML, Green TJ, Skeaff CM: Plasma and erythrocyte fatty acids reflect intakes of saturated and $n-6$ PUFA within a similar time frame. J Nutr 2014, 144(1):33-41.

31. Higgins JP, Altman DG, Gotzsche PC, Juni P, Moher D, Oxman AD, Savovic J, Schulz KF, Weeks L, Sterne JA, Cochrane Bias Methods Group, Cochrane Statistical Methods Group: The Cochrane Collaboration's tool for assessing risk of bias in randomised trials. BMJ 2011, 343:d5928.

32. Bradburn MJ, Deeks JJ, Berlin JA, Russell Localio A: Much ado about nothing: a comparison of the performance of meta-analytical methods with rare events. Stat Med 2007, 26(1):53-77.

33. Higgins JP, Thompson SG: Quantifying heterogeneity in a meta-analysis. Stat Med 2002, 21(11):1539-1558.

34. Leng GC, Lee AJ, Fowkes FG, Jepson RG, Lowe GD, Skinner ER, Mowat BF: Randomized controlled trial of gamma-linolenic acid and eicosapentaenoic acid in peripheral arterial disease. Clin Nutr 1998, 17(6):265-271.

35. Carrero JJ, Lopez-Huertas E, Salmeron LM, Baro L, Ros E: Daily supplementation with ( $n-3)$ PUFAs, oleic acid, folic acid, and vitamins B-6 and E increases pain-free walking distance and improves risk factors in men with peripheral vascular disease. J Nutr 2005, 135(6):1393-1399.

36. Carrero JJ, López-Huertas E, Salmerón LM, Ramos VE, Baró L, Ros E: Simvastatin and supplementation with $\omega-3$ polyunsaturated fatty acids and vitamins improves claudication distance in a randomized PILOT study in patients with peripheral vascular disease. Nutr Res 2006, 26(12):637-643.

37. Gans RO, Bilo HJ, Weersink EG, Rauwerda JA, Fonk T, Popp-Snijders C, Donker AJ: Fish oil supplementation in patients with stable claudication. Am J Surg 1990, 160(5):490-495.

38. Ishikawa Y, Yokoyama M, Saito Y, Matsuzaki M, Origasa H, Oikawa S, Sasaki J, Hishida H, Itakura H, Kita T, Kitabatake A, Nakaya N, Sakata T, Shimada K, Shirato K, Matsuzawa Y, JELIS Investigators: Preventive effects of eicosapentaenoic acid on coronary artery disease in patients with peripheral artery disease. Circ J 2010, 74(7):1451-1457.

39. Pan A, Chen M, Chowdhury R, Wu JH, Sun Q, Campos H, Mozaffarian D, Hu FB: alpha-Linolenic acid and risk of cardiovascular disease: a systematic review and meta-analysis. Am J Clin Nutr 2012, 96(6):1262-1273.

40. Chowdhury R, Stevens S, Gorman D, Pan A, Warnakula S, Chowdhury S, Ward $\mathrm{H}$, Johnson L, Crowe F, Hu FB, Franco OH: Association between fish consumption, long chain omega 3 fatty acids, and risk of cerebrovascular disease: systematic review and meta-analysis. BMJ 2012, 345:e6698.

41. Cao H, Wang X, Huang H, Ying SZ, Gu YW, Wang T, Huang CX: Omega-3 fatty acids in the prevention of atrial fibrillation recurrences after cardioversion: a meta-analysis of randomized controlled trials. Intern Med 2012, 51(18):2503-2508.

42. He Z, Yang L, Tian J, Yang K, Wu J, Yao Y: Efficacy and safety of omega-3 fatty acids for the prevention of atrial fibrillation: a meta-analysis. Can J Cardiol 2013, 29(2):196-203.

43. Kromhout D, de Goede J: Update on cardiometabolic health effects of omega-3 fatty acids. Curr Opin Lipidol 2014, 25(1):85-90.

44. Pase MP, Grima NA, Sarris J: Do long-chain $n-3$ fatty acids reduce arterial stiffness? A meta-analysis of randomised controlled trials. Br J Nutr 2011, 106(7):974-980.

45. Iso H, Kobayashi M, Ishihara J, Sasaki S, Okada K, Kita Y, Kokubo Y, Tsugane S, JPHC Study Group: Intake of fish and n3 fatty acids and risk of coronary heart disease among Japanese: the Japan Public Health Center-Based (JPHC) Study Cohort I. Circulation 2006, 113(2):195-202.

46. Kobayashi M, Sasaki S, Kawabata T, Hasegawa K, Tsugane S, JPHC: Validity of a self-administered food frequency questionnaire used in the 5-year follow-up survey of the JPHC Study Cohort I to assess fatty acid intake: comparison with dietary records and serum phospholipid level. J Epidemiol 2003, 13(1 Suppl):S64-S81.

47. LaRosa JC, He J, Vupputuri S: Effect of statins on risk of coronary disease: a meta-analysis of randomized controlled trials. JAMA 1999, 282(24):2340-2346.
48. Joint FAO/WHO Expert Consultation on Fats and Fatty Acids in Human Nutrition: Interim Summary of Conclusions and Dietary Recommendations on Total Fat \& Fatty Acids. http://www.who.int/nutrition/topics/ FFA_interim_recommendations/en/.

49. De Caterina R: N-3 fatty acids in cardiovascular disease. N Engl J Med 2011, 364(25):2439-2450

50. Campbell A, Price J, Hiatt WR: Omega-3 fatty acids for intermittent claudication. Cochrane Database Syst Rev 2013, 7:CD003833.

doi:10.1186/1471-2261-14-70

Cite this article as: Enns et al:: The impact of omega-3 polyunsaturated fatty acid supplementation on the incidence of cardiovascular events and complications in peripheral arterial disease: a systematic review and meta-analysis. BMC Cardiovascular Disorders 2014 14:70.

\section{Submit your next manuscript to BioMed Central and take full advantage of:}

- Convenient online submission

- Thorough peer review

- No space constraints or color figure charges

- Immediate publication on acceptance

- Inclusion in PubMed, CAS, Scopus and Google Scholar

- Research which is freely available for redistribution 